\title{
Land Surface Temperature Retrieval Based on Landsat ETM+/TM-- Taking Xi'an City as an Example
}

\author{
Chen Qiuji* and Li Chuting
}

College of Geomatics, Xi'an University of Science and Technology, Xi'an, 710054, P.R. China

\begin{abstract}
The development of remote sensing technology and geographic information systems provides a new research tool for people to quickly access urban heat environmental information and analysis the evolution of space. Combined with urban development planning data related information of Xi'an, then the LST of Xi'an urban area was successfully retrieved by the mono-window algorithm based on 2002 ETM + and 2010 TM images. The results indicated that there was a weak heat island effect in most districts of $\mathrm{Xi}^{\prime}$ an, only a small portion of the region where there was a strong heat island effect. In 2002, the temperature between suburbs district and urban district in Xi'an was about $24^{\circ} \mathrm{C}-30^{\circ} \mathrm{C}$, the same as 2010. But in 2010, the area of heat island effect was much smaller than 2002. Finally, the correlation between NDVI and LST was also analyzed, and results concluded that the LST retrieved from the ETM+/TM data had a strong negative correlation with NDVI. Therefore, increasing vegetation area in urban can help alleviate the heat island effect.
\end{abstract}

Keywords: Heat island effect, land surface temperature, landsat ETM+/TM, mono-window algorithm.

\section{INTRODUCTION}

Nowadays, urban heat island effect (UHI) is one of the most important urban ecological problems. The road made of asphalt and cement has a greater power at conducting and storing thermal energy than grass and soil because of their compact and homogenous structure. Along with the rapid urbanization, there are many crowed building group that makes the urban feels hotter. The reduction of evaporation makes the urban store more heat, so it radiates to the surrounding and the atmosphere that causing the temperature of urban is generally higher than suburban at the same time. High temperatures urban is surrounded by low temperature suburban. What mentioned above is the formation of the urban heat island effect (UHI) [1]. Development of satellite remote sensing technology and geographic information systems provides a new research tool for quick access to environmental information and spatial urban heat evolution analysis. Landsat ETM+ and TM data was used this paper to calculate LST of Xi' an and hope to play a role in living environment planning and urban planning.

\section{STUDY AREA AND DATA SOURCE}

Xi'an is located in the Guanzhong Basin which is in the central of Weihe Valley. The average elevation of Xi'an is 445 meters. The Loess Plateau and Weihe Valley are to the west of Xi'an and Qinling Mountain is to the south of it. Xi'an is characterized by the warm temperate of semi-humid continental monsoon climate, so it has four distinctive seasons. In 2013, Xi'an minimum temperature was $-12^{\circ} \mathrm{C}$ and the maximum temperature was $39^{\circ} \mathrm{C}$. It covers an area of
10.11 thousands square kilometers with a population of 8.55 million. As Xi'an region is an important city of international tourism, research LST at a regional scale based on remote sensing techniques has a positive significance for the urban planning and the development of tourism.

In this study, Landsat-7 ETM+ data provided by USGS were acquired at 03:08 on 3 June, 2002, with a track number of 127/36. Landsat-5 TM data provided by USGS were acquired at 03:10 on 4 August, 2010. Landsat-7 ETM+ has a total of 8 bands, $30 \mathrm{~m}$ spatial resolution, of which the sixth band (thermal infrared) resolution is $60 \mathrm{~m}$, the eighth band resolution of $15 \mathrm{~m}$. Landsat- $5 \mathrm{TM}$ has a total of 7 bands, spatial resolution of $30 \mathrm{~m}$, of which the sixth band (thermal infrared) resolution is $120 \mathrm{~m}$.

\section{LST RETRIEVAL METHOD BASED ON QIN'S MONO-WINDOW ALGORITHM}

The mono-window algorithm [2] was provided by Qin Zhihao according to the transfer equation of the land surface thermal radiation using Landsat Landsat data. There was three unknown parameters in the formula of the algorithm. They were respectively Ta, $\tau, \varepsilon$. Ta was the average atmospheric temperature, $\tau$ was the atmospheric transmittance and $\varepsilon$ was ground emissivity. Formulas of Qin's mono-window algorithm can be expressed as Eq.1

$\mathrm{T}_{\mathrm{s}}=\left[\mathrm{a} *(1-\mathrm{C}-\mathrm{D})+(\mathrm{b} *(1-\mathrm{C}-\mathrm{D})+\mathrm{C}+\mathrm{D}) * \mathrm{~T}_{6}-\mathrm{D} * \mathrm{~T}_{\mathrm{a}}\right] / \mathrm{C}$

where $T_{s}$ was LST, $T_{6}$ was the pixel brightness temperature of TM6 and $\mathrm{L}_{(\lambda)}$ was the corresponding intensity of thermal radiation, $a=-67.355351, b=0.458606, C$ and $D$ was the intermediate variable. $\mathrm{C}$ and $\mathrm{D}$ can be simplified as Eq. 2 and Eq.3

$\mathrm{C}=\tau^{*} \varepsilon$ 
$\mathrm{D}=(1-\tau) *(1+\tau *(1-\varepsilon))$

\subsection{Approximation of Ta} [3]:

Ta can be calculated according to the following formula

In the middle latitude area, the average value of $\mathrm{Ta}$ in summer $\left(45^{\circ} \mathrm{N}\right.$, July $)$ can be calculated by Eq. 4

$\mathrm{T}_{\mathrm{a}}=16.0110+0.92621 * \mathrm{~T}_{0}$

In the winter of middle latitude, the average value of Ta can be calculated by Eq. 5

$\mathrm{T}_{\mathrm{a}}=19.2704+0.91118 * \mathrm{~T}_{0}$

The average atmospheric temperature Ta can be derived through check out the annual mean temperature of the day that Landsat data was be obtained. $\tau$ can be supplied from Atmospheric Correction Parameter Calculator which offered by the official website of NASA, as long as input the Landsat data acquisition time and the center longitude and latitude, the estimated value of $\tau$ can be obtained. It can be also estimated according to different atmospheric water vapor content in different temperature conditions.

\subsection{Estimation of the Ground Emissivity}

In Qin's mono-window algorithm [4], the modified NDVI threshold method was used to calculate the value of $\varepsilon$. the land surface was divided into three kinds of cover types. They were: water body, town (road, industrial and mining district, city and rural residential area), natural surface (including bare land, grassland and arable land). NDVI was the best indicator of vegetation growth status and vegetation coverage.

$\mathrm{NDVI}=\left(\mathrm{DN}_{\mathrm{NR}}-\mathrm{DN}_{\mathrm{R}}\right) /\left(\mathrm{DN}_{\mathrm{NR}}+\mathrm{DN}_{\mathrm{R}}\right)$

Vegetation cover $P_{v}$ refers to the percentage of vertical projection area of the ground of vegetation (including leaves, stems, branches) in total statistical area (Gitelson et al., 2002).

\section{$\mathrm{P}_{\mathrm{v}}=\left[\left(\mathrm{NDVI}-\mathrm{NDVI}_{\mathrm{s}}\right) /\left(\mathrm{NDVI}_{\mathrm{v}}-\mathrm{NDVI}_{\mathrm{s}}\right)\right]$}

In Eq.7, $\mathrm{NDVI}_{\mathrm{v}}=0.7, \mathrm{NDVI}_{\mathrm{s}}=0.5 . \mathrm{NDVI}_{\mathrm{v}}$ was NDVI value of pure vegetation area or agricultural land, and $\mathrm{NDVI}_{\mathrm{s}}$ was bare soil or little vegetation covering area. When NDVI $>0.7$, pixel can be regarded as full vegetation cover, $\mathrm{P}_{\mathrm{v}}$ should be 1. If Pixel was considered to be of mixed pixels consisting of bare soil and vegetation, such as the town pixel, then $\mathrm{NDVI}_{\mathrm{V}}$ and $\mathrm{NDVI}_{\mathrm{S}}$ were assigned between 0.7 and 0.05 . Therefore, When NDVI $<0.05$, it can be regarded as bare soil, $\mathrm{P}_{\mathrm{v}}$ should be 0 . Water body pixel of ground emissivity value can directly take 0.995 according to experience.

Vegetation $\left(\varepsilon_{\text {surface }}\right)$ and towns ( $\left.\varepsilon_{\text {build-up }}\right)$ ground emissivity can be calculated according to the following Eq. 8 and Eq. 9 .

$\varepsilon_{\text {surface }}=0.9625+0.0614 \mathrm{P}_{\mathrm{v}}-0.0461 \mathrm{P}_{\mathrm{v}}{ }^{2}$

$\varepsilon_{\text {build-up }}=0.9589+0.086 \mathrm{P}_{\mathrm{v}}-0.0671 \mathrm{P}_{\mathrm{v}}^{2}$

\subsection{Calculation for $T_{6}$}

$\mathrm{T}_{6}$ was the pixel brightness temperature of TM6, referred to the black-body temperature that black-body radiated the same energy equal with observation objects.
$\mathrm{T}_{6}=\mathrm{K}_{2} / \ln \left(1+\mathrm{K}_{1} / \mathrm{L}_{(\lambda)}\right)$

$\mathrm{L}_{(\lambda)}=\mathrm{L}_{\min (\lambda)}+\left(\mathrm{L}_{\max (\lambda)}-\mathrm{L}_{\min (\lambda)}\right) \mathrm{Q}_{\mathrm{dn}} / \mathrm{Q}_{\max }$

$\mathrm{Q}_{\mathrm{dn}}$ referred to the Digital Number (DN) values recorded

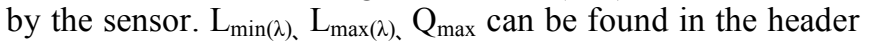
file of remote sensing image. The formula can be written as Eq.12

$\mathrm{L}_{(\lambda)}=1.238+0.05515686 \mathrm{Q}_{\mathrm{dn}}$

For Landsat-5 TM $\mathrm{K}_{1}=607.76 \mathrm{~W} \cdot \mathrm{m}^{-2} \cdot \mathrm{sr}^{-1} \cdot \mu \mathrm{m}^{-1} \quad \mathrm{~K}_{2}=$ 1260.56K

For Landsat-7 ETM $+\mathrm{K}_{1}=666.09 \mathrm{~W} \cdot \mathrm{m}^{-2} \cdot \mathrm{sr}^{-1} \cdot \mu \mathrm{m}^{-1} \mathrm{~K}_{2}=$ $1282.71 \mathrm{~K}$

One point should be mentioned that Landsat-7 ETM provided two mode of thermal infrared data $: 6 \mathrm{H}$ and $6 \mathrm{~L}$. So in the calculation of $\mathrm{L}_{(\lambda)}$, the value of corresponding $\mathrm{L}_{\min (\lambda)}$ and $\mathrm{L}_{\max (\lambda)}$ need to check out before calculation. $6 \mathrm{H}$ channel's available temperature was range of $240 \sim 320 \mathrm{~K}$. 6L channel's available temperature was range of $130 \sim 350 \mathrm{~K}$. The $6 \mathrm{H}$ channel was more suitable for the inversion of LST under the normal condition and the inversion accuracy was higher than that of 6L channel [5].

\section{RESULTS AND DISCUSSION}

Figs. (1) and (2) were LST of Xi'an by using Qin's mono window algorithm in August 2002 and August 2010. It can be see from the pictures that temperature of urban was higher than suburb. In both of two figures most area of Xi'an in $24^{\circ} \mathrm{C}-27^{\circ} \mathrm{C}$.

\subsection{Analysis of the Intensity Distribution of Heat Island}

Zhang Yong [6] presented a new index to describe the thermal field variation of a certain point:

$\mathrm{HI}(\mathrm{T})=\left(\mathrm{T}-\mathrm{T}_{\text {MEAN }}\right) / \mathrm{T}_{\text {MEAN }}$

In the Eq.13, HI referred to urban thermal field variance index, $\mathrm{T}$ was LST of somewhere in Xi'an, $\mathrm{T}_{\text {MEAN }}$ was average LST of study area. According to the thermal field variance index and the actual situation, the value of $\mathrm{HI}$ can be divided into 4 types with different color in the Figs. (3) and (4).

(1) The value of blue area HI (T) was negative, indicating no heat island effect

(2) The value of yellow area HI (T) was in $0-0.1$, indicating weak heat island effect

(3) The value of magenta HI (T) was in 0.1-0.2, indicating heat island effect

(4) The value of red HI (T) was beyond 0.2 , indicating strong island effect

Comparing with 2010, in 2002, it can be found that the area of no heat island effect in 2002 and 2010 were both appeared on the agricultural land in the suburbs, but area in 2002 was larger than in 2010 , then, heat island effect was more serious in 2002 than 2010. In 2010 most area in Xi'an was in weak heat island effect, a small area in heat island effect. The area in strong heat island effect were Xi'an Railway Station, Sanfuwan Passenger station and other crowed places. 


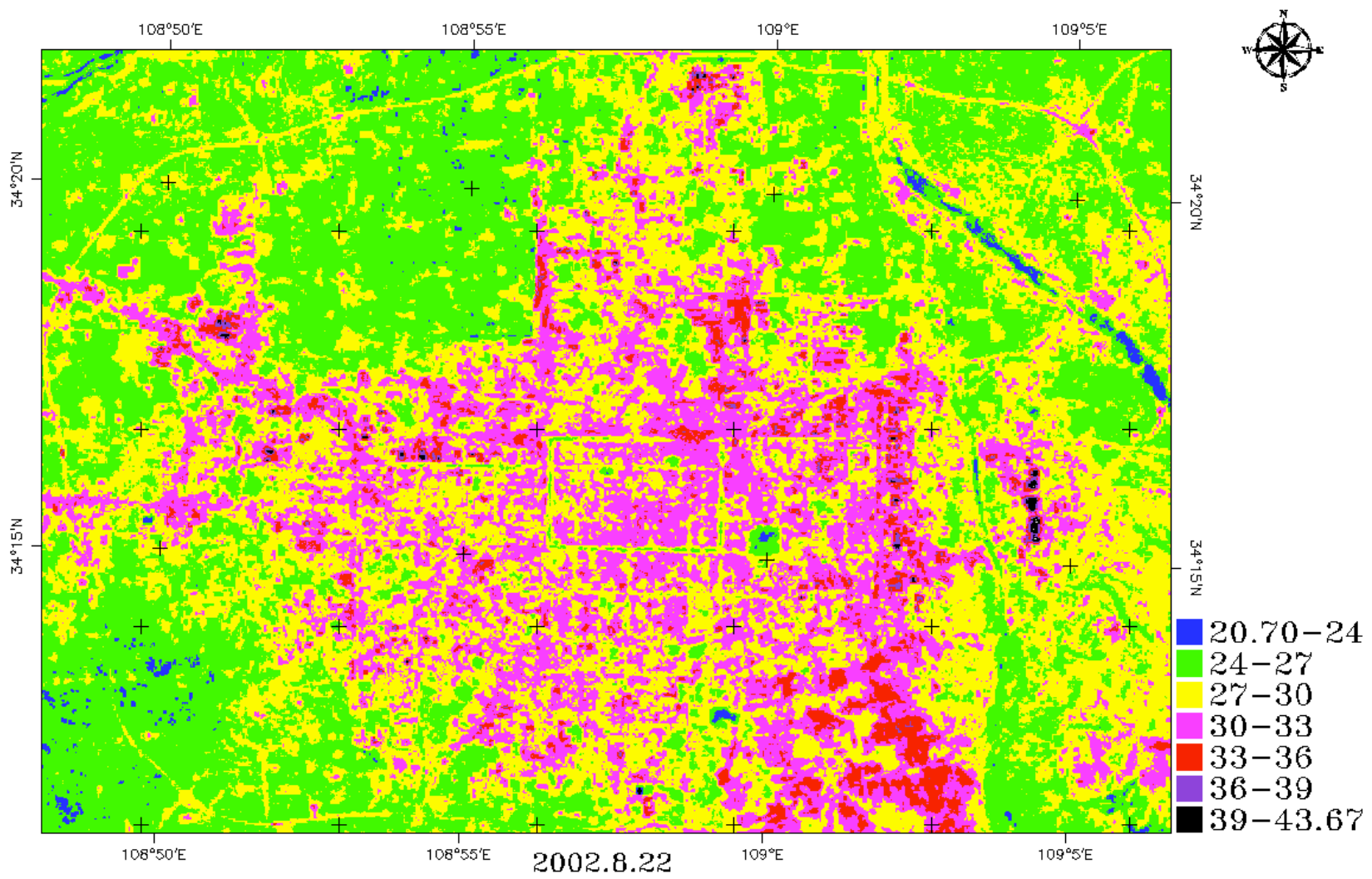

Fig. (1). LST of Xi' an in 2002.

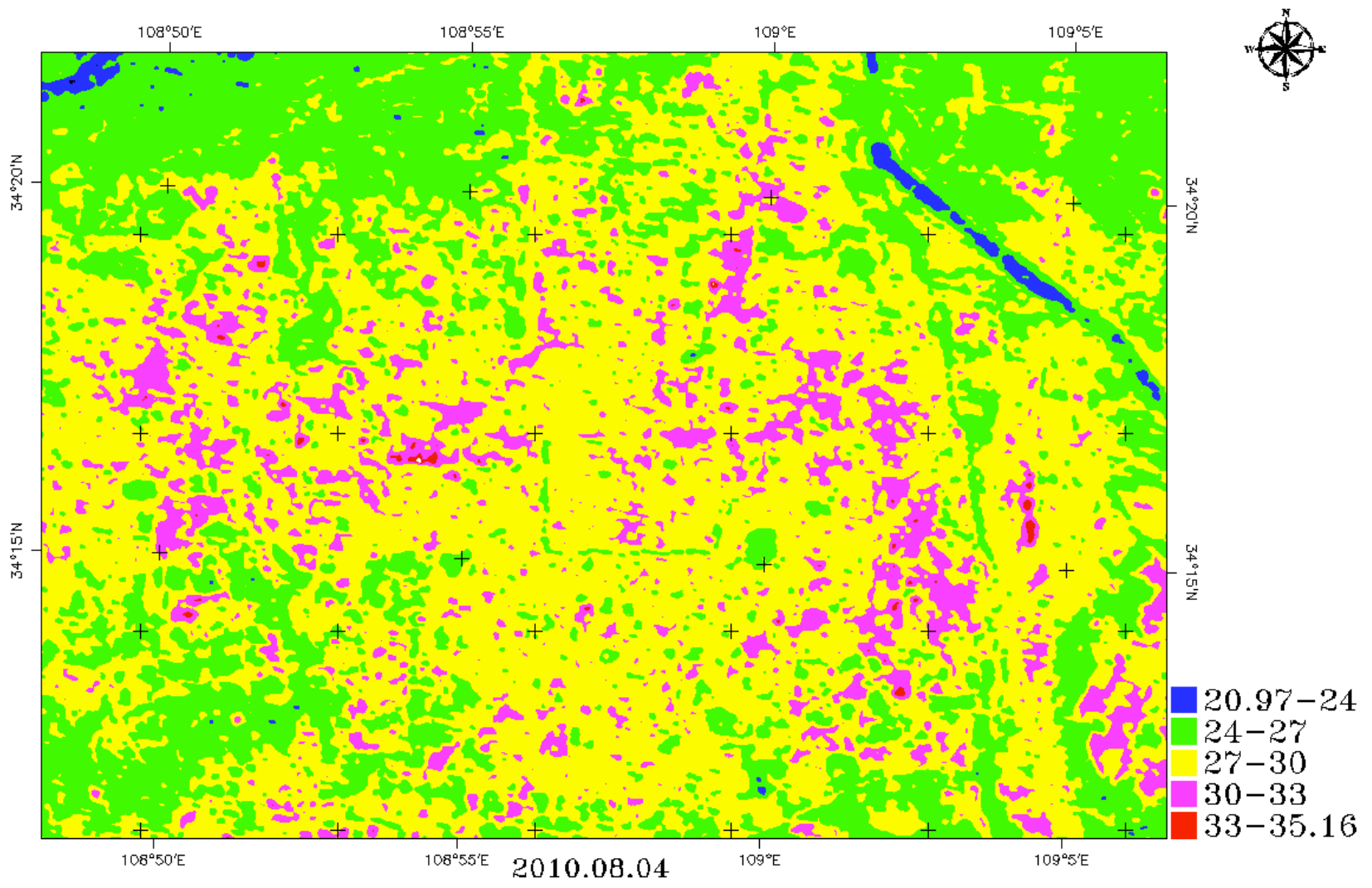

Fig. (2). LST of Xi' an in 2010. 


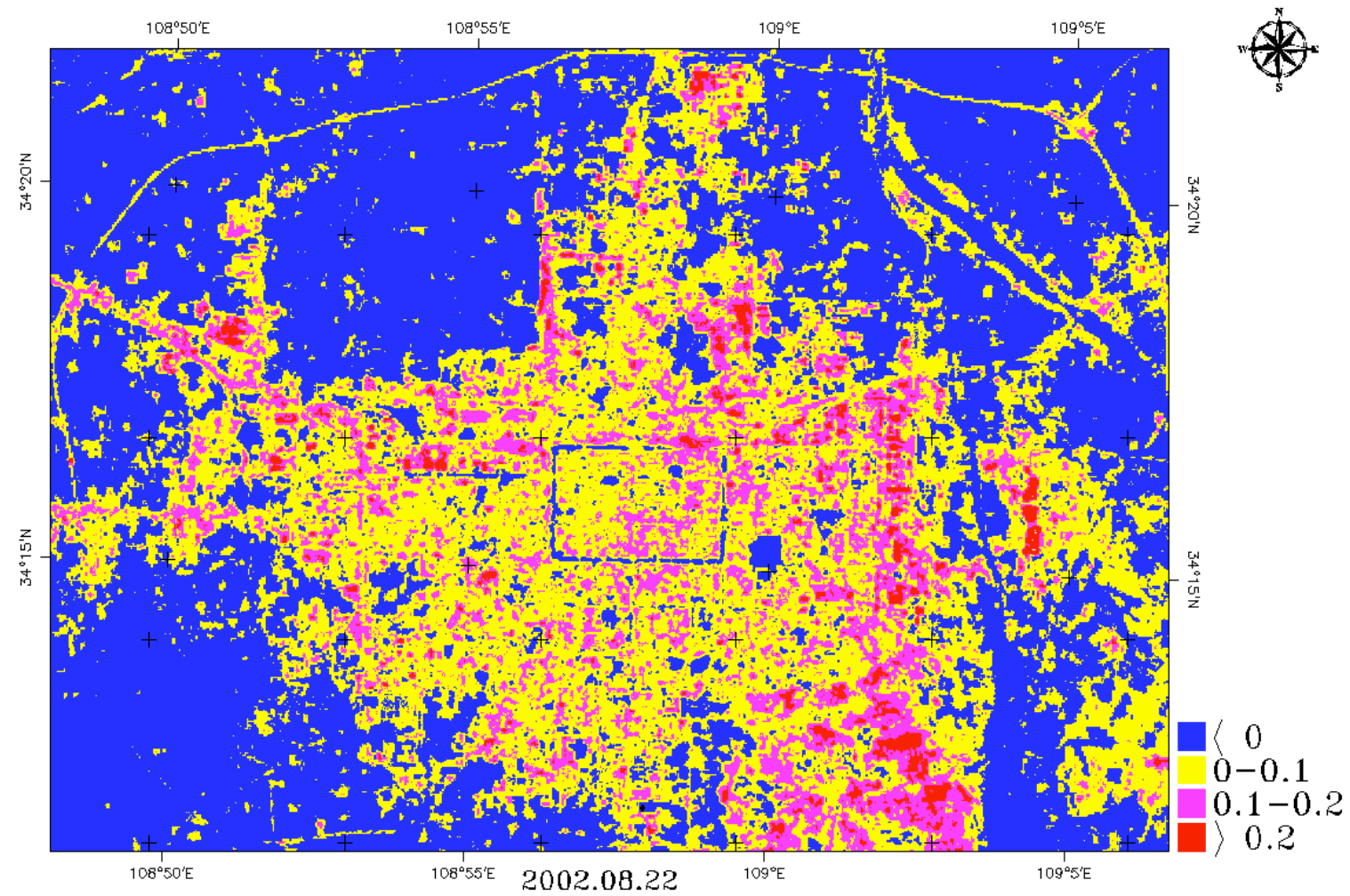

Fig. (3). Distribution of heat island in 2002.

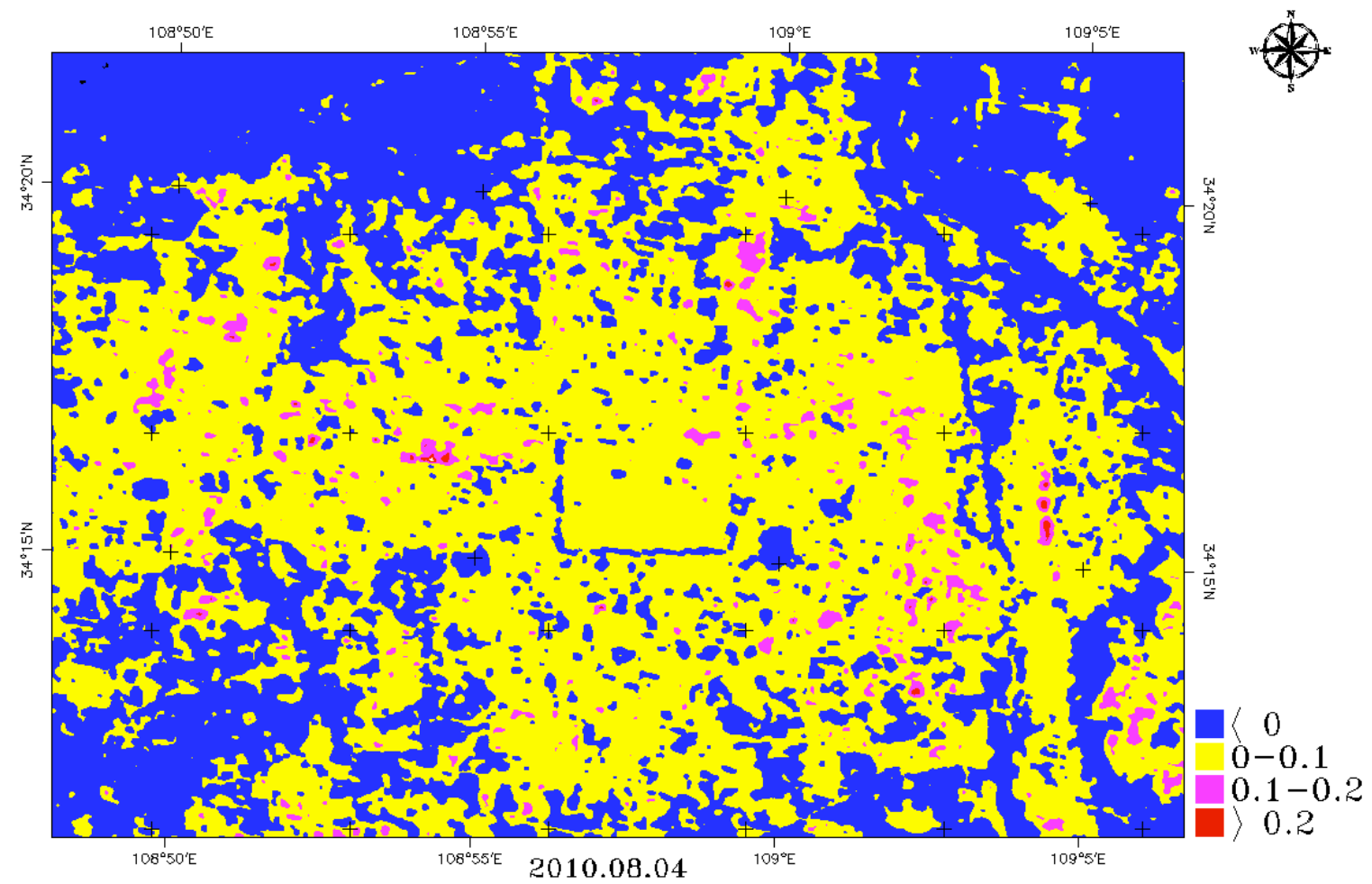

Fig. (4). Distribution of heat island in 2010.

\subsection{Analysis of NDVI and LST}

In order to analyze the relationship between the NDVI and LST, Scatter plots and linear fitting were done between LST values of 250 random ground pixels (except water pixel) and the corresponding NDVI value. Statistical analysis showed (Fig. 5) that the correlation coefficient between NDVI index and land surface temperature LST reached $0.502, \mathrm{R}^{2}=0.252$, which meant that there was significant 


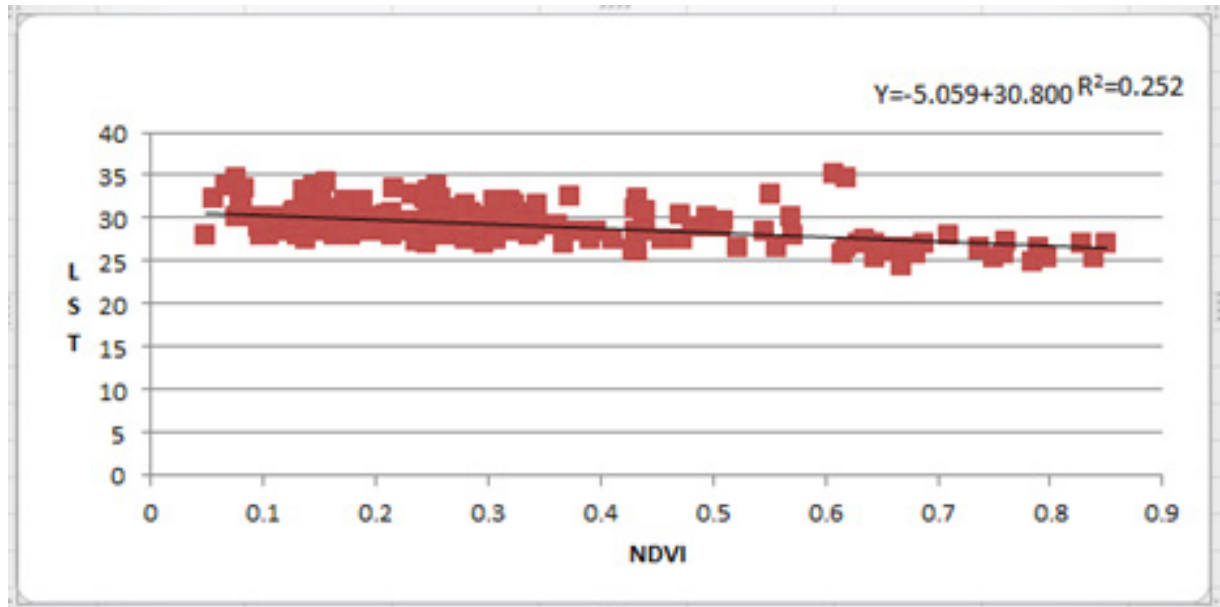

Fig. (5). Correlation of NDVI\&LST.

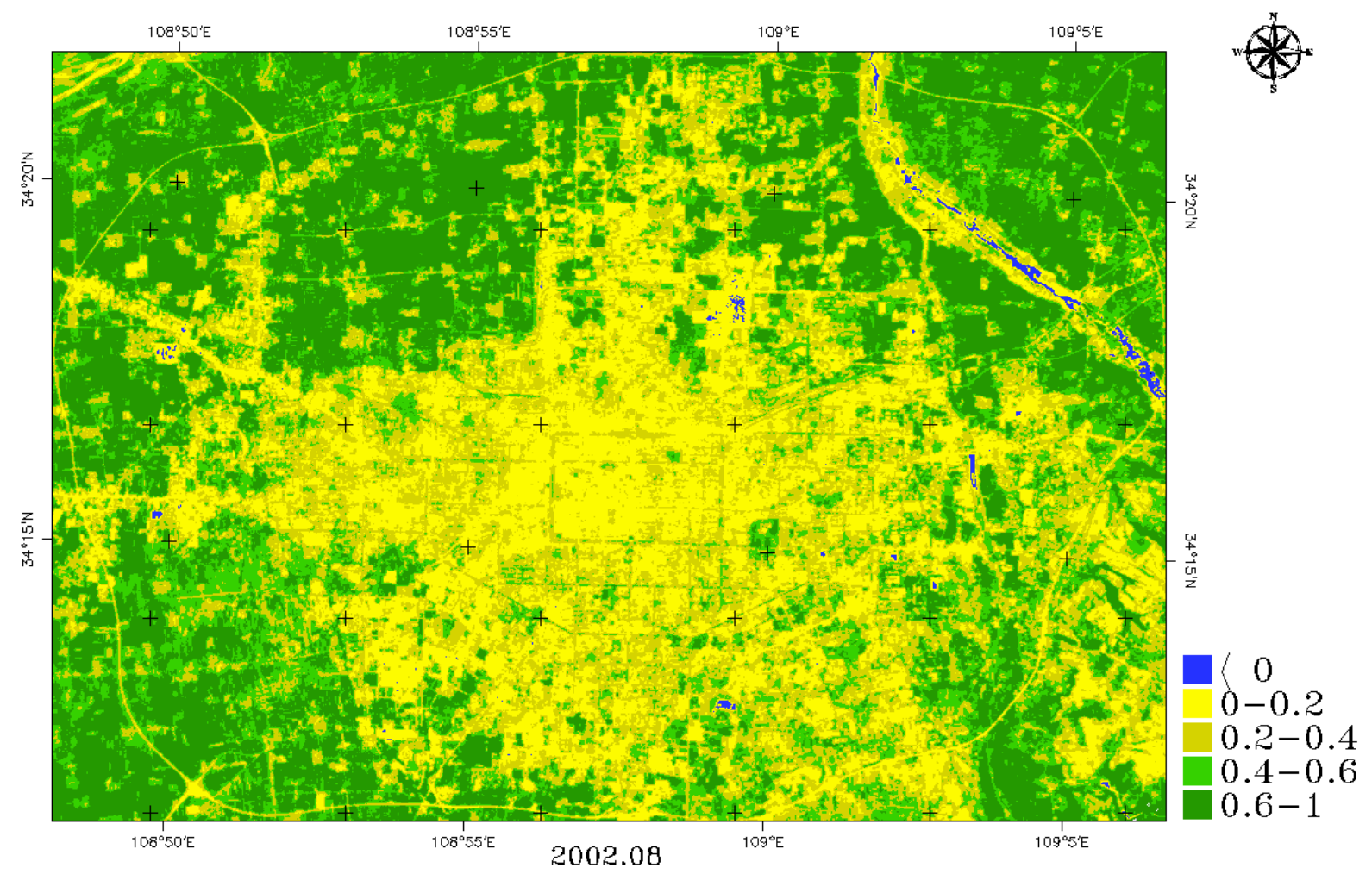

Fig. (6). NDVI of Xi' an in 2002.

negative correlation between land surface temperature and vegetation index.

From the following Figs. (6) and (7), it can be seen that outside of city center area, the NDVI index was significantly higher than the city center area, and from the above data, it can also be learned that the LST of the city center area was higher than suburb. In 2002, the area within the second ring of Xi'an City, NDVI value was in the range of 0-0.2. In 2010, the area within the by-pass highway of Xi'an, NDVI value was in the range of $0.2-0.4$, indicated that the $\mathrm{Xi}^{\prime}$ an urban green space system in 2010 was better than in 2002 . But water body exceptions, the NDVI value of the water and temperature values were relatively low. Now the Xi'an city green rate was $31.89 \%$, green coverage rate was $40.33 \%$, the per capita green area was $7.8 \mathrm{~m}^{2}$. According to statistics,
$\mathrm{Xi}$ 'an had 6 nature reserves, 7 types of wetlands, the total area was about 23577.8 hectares. The park in Xi'an had reached a total number of 54, built-up area of about 2625 hectares. The protection forest in the second south ring and second north ring had been built. Green space effect of Qujiang New District, Gaoxin District, and EconomicTechnological Development Area were obvious and green status level was higher than other districts [7]. To ease the urban heat island effect, green space area and water area shall be increased or improve the green vegetation coverage.

\subsection{Analysis of Xi'an Urban Planning}

Land types of Xi'an were divided into 4 types: construction land, agricultural land, water, bare land and unused land by supervised classification method. The following Figs. (8) 


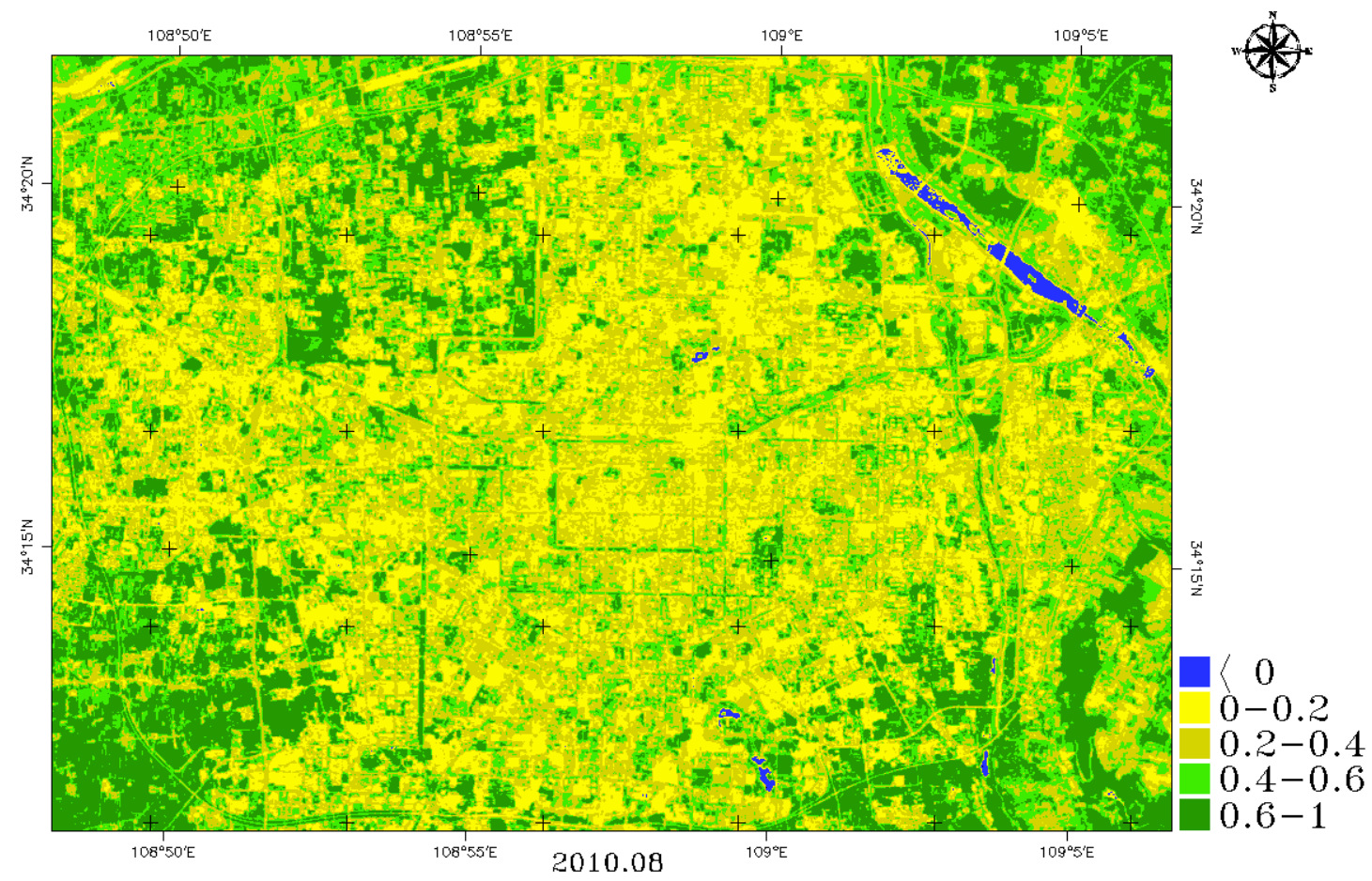

Fig. (7). NDVI of Xi' an in 2010.

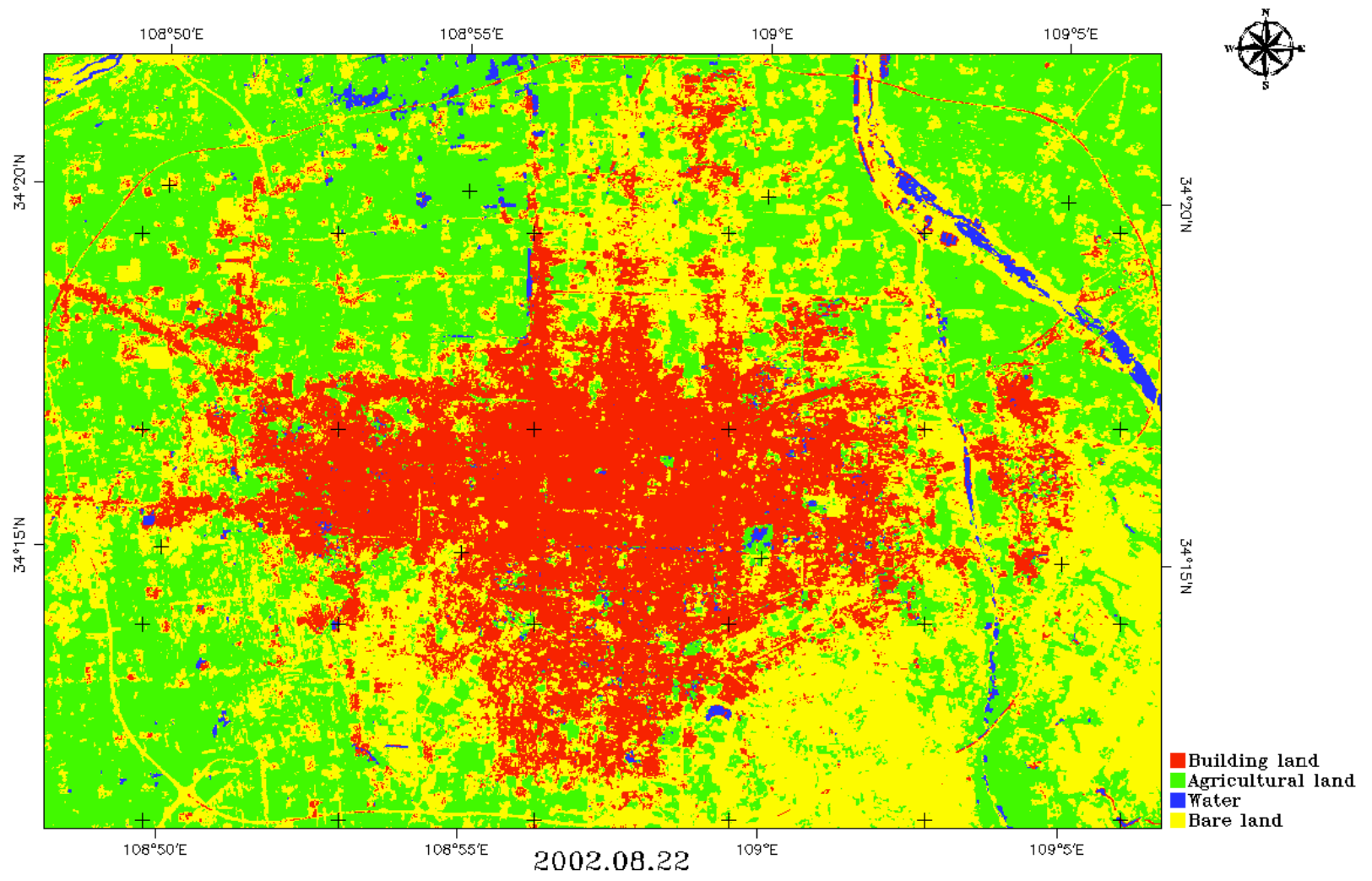

Fig. (8). Distribution of land use type in 2002.

and (9) were corresponding to distribution of land use type in 2002 and 2010. The red area was the construction land, the green area was agricultural land, the yellow area was the bare land and unused land, the blue area was water. According to the statistical data in ENVY, construction land in 2002 accounted for $22.82 \%$ of the total area of Xi'an, but in 2010 it accounted for $52.57 \%$ of the total area, agricultural land decreased from $40.92 \%$ in 2002 to $35.05 \%$ in 2010 , the bare land and unused land, water area were also reduced from $34.80 \%$ to $11.45 \%, 1.46 \%$ to $0.93 \%$. Comparison of the 


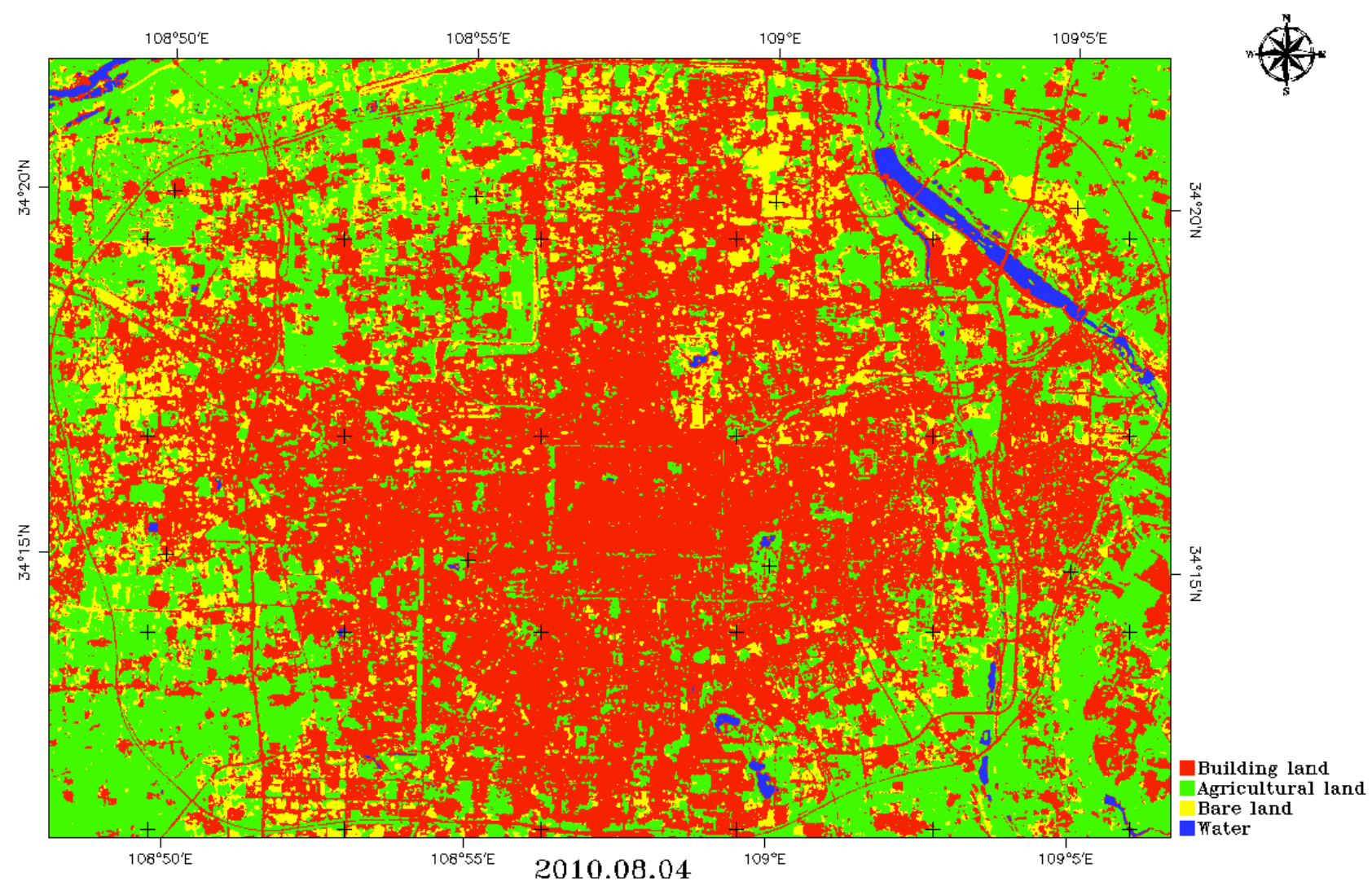

Fig. (9). Distribution of land use type in 2010.

2010 and 2002 figure on LST of Xi'an, we can see that, the construction land in general was in area of weak heat island effect or heat island effect, but most of agricultural land was in the area of without heat island effect.

\section{STRATEGY FOR IMPROVEMENT}

\subsection{Increasing the City Green Space and Water Area}

In large energy consumption place, such as Heping industrial park and Xidian Group had a significant effect on reducing local environmental temperature through the introduction of water or increase the green space area. Planting green plants may provide more advantages than water, because plants may not be influenced by topography, have high economic benefit, can purify the air, also have a great role in reducing the urban noise. Planting on the roofs of tall buildings can not only reduce the absorption of heat energy, but also beautify the city. For some materials of the heavy endothermic wall decoration may consider the possibility of change into other cooling and energy-saving materials. Increase the construction of downwind street pattern to drive air circulation to reduce the local temperature. The strongest cooling effect in the common city layout was wedge-shaped, which not only has good connectivity but also can achieve the "corridor effect" of landscape ecological [8].

\subsection{Reducing Artificial Heat Emission from the Clean Production}

Asphalt and cement road has a greater power at conducting and storing thermal energy than grass and soil because of their compact that is one of the reason why temperature in urban is higher than suburb. So using some strong permeability materials in ground pavement can reduce the absorption of solar radiation and reduce the heat storage. Advocating people to travel by public transport or other low-carbon way. and Xi'an subway construction makes the traffic conditions even worse, so advocate low-carbon way can relieve traffic congestion situation.

\section{CONCLUSION}

(1) Range of influence by heat island effect in year 2010 was bigger than in year 2002, but the heat island intensity level was weaker than in year 2002. The main reason was that in year 2002 the construction of Xi'an city urban green space system had not been perfect. In 2010, most values of NDVI were in the range of $0.2-0.4$, but in 2002, most values of NDVI were in the range of $0-0.2$. It has been proved that there was a negative correlation between NDVI and LST, so the strength grade of Xi'an urban heat island effect in 2010 was weak than in 2002.

(2) In the place of urban villages, industrial zone of high energy consumption, population density of the train station, passenger stations, where it is easy to form the heat island effect.

(3) City green space system and water has obvious effect to reduce heat island effect [9].

However, due to the absence of measured data of land surface temperature of Xi'an, the experimental results still need further verification. 


\section{CONFLICT OF INTEREST}

The authors confirm that this article content has no conflict of interest.

\section{ACKNOWLEDGEMENTS}

This work was financially supported by The Special Funds of Public Welfare Projects of the Ministry of Land and Resources (No. 201511005).

\section{REFERENCES}

[1] J. Zhang, Urban Thermal Environment Remote Sensing, Beijing: Meteorological Press, 2010, pp. 22-23.

[2] Z. Qin, A. Karnieli and P. Berliner, "Mono-window algorithm for retrieving land surface temperature from landsat TM6 data", ACTA Geographica Sinica, vol. 56, pp. 456-466, July 2001.

[3] Z. Qin, W. Li, M. Zhang, A. Karnieli, and P. Berliner, "Estimating of the essential atmospheric parameters of mono-window algorithm for land surface temperature retrieval from landsat Tm6", Remote Sensing for Land \& Resources, vol. 56, pp. 37-43, June 2003.
[4] Z. Qin, W. Li, B. Xu, Z Chen, and J. Liu, "The estimation of land surface emissivity for landsat TM6 ", Remote Sensing for Land \& Resources, vol. 61, pp. 28-41, Sept. 2004.

[5] C. Liu, X. Lu, and S. Gao, "Comparison of brightness temperatures inversed from high and low gain state data of lansat - 7 ETM + thermal infrared band", Journal of Henan Polytechnic University ( Natural Science), vol. 30, pp. 561-566. Oct. 2011.

[6] Y. Zhang, T. Yu, H. Gu, Y. Zhang, L. Chen, S. Yu, W. Zhang, and $\mathrm{X}$. Li, "Land surface temperature retrieval from CBERS-02IRMSS thermal infrared data and its applications in quantitative analysis of urban heat island effect", Journal of Remote Sensing, vol. 10, pp. 790-797, Sep. 2006.

[7] H. Shi, "The research on ecological garden city of Xi'an's urban green space system", MS thesis, Northwest Agriculture \& Forestry University, Yangling, China, 2013.

[8] Y. Liu, and J. Guo, "Numerical simulation for the influence of green space patterns on urban thermal environment: taking taiyuan city as an example", China Environmental Science, vol. 31, pp. 1403-1408, Sept. 2011.

[9] F. Wu, S. Li, and J. Liu, "Research on the relationship between urban green spaces of different areas and the temperature and humidity benefit", Chinese Landscape Architecture, vol. 6, pp. 71-74, June 2007.

Received: September 16, 2014

Revised: December 23, 2014

Accepted: December 31, 2014

(C) Qiuji and Chuting; Licensee Bentham Open.

This is an open access article licensed under the terms of the Creative Commons Attribution Non-Commercial License (http://creativecommons.org/licenses/by-nc/3.0/) which permits unrestricted, non-commercial use, distribution and reproduction in any medium, provided the work is properly cited. 